RE: MS \#HEP-11-1745.R2

\title{
HLA Class II Molecules Confer both Susceptibility and Progression in Japanese Patients with Primary Biliary Cirrhosis
}

\author{
Takeji Umemura, ${ }^{1}$ Satoru Joshita, ${ }^{1}$ Tetsuya Ichijo, ${ }^{1}$ Kaname Yoshizawa, ${ }^{1,4}$ \\ Yoshihiko Katsuyama, ${ }^{2}$ Eiji Tanaka, ${ }^{1}$ Masao Ota,${ }^{3}$ The Shinshu PBC Study Group
}

1: Department of Medicine, Division of Hepatology and Gastroenterology, Shinshu University School of Medicine, Matsumoto, Japan

2: Department of Pharmacy, Shinshu University Hospital, Matsumoto, Japan

3: Department of Legal Medicine, Shinshu University School of Medicine, Matsumoto, Japan

4: Department of Gastroenterology, NHO Shinshu Ueda Medical Center, Ueda, Japan

Key words: PBC, OLT, protection, susceptibility, genetic 
Corresponding author: Takeji Umemura, MD, PhD, Department of Medicine, Shinshu University School of Medicine, 3-1-1 Asahi, Matsumoto 390-8621, Japan

E-mail: tumemura@shinshu-u.ac.jp; Tel: +81-263-37-2634; Fax: +81-263-32-9412 and Masao Ota, PhD, Department of Legal Medicine, Shinshu University School of Medicine, 3-1-1 Asahi, Matsumoto 390-8621, Japan

E-mail: otamasao@shinshu-u.ac.jp; Tel: +81-263-37-3217; Fax: +81-263-37-3084

Abbreviations: $\mathrm{PBC}$, primary biliary cirrhosis; OR, odds ratio; $\mathrm{Cl}$, confidence interval;

OLT, orthotopic liver transplantation

Financial support: The Ministry of Education, Culture, Sports, Science, and Technology of Japan (23590969) and The Ministry of Health, Labor, and Welfare of Japan

Conflicts of interest: The authors disclose no conflicts.

The Shinshu PBC Study Group: Yuki Ichikawa-Yamada, Takefumi Kimura, Susumu Morita, Atsushi Kamijo, Michiharu Komatsu, Akihiro Matsumoto (Shinshu University School of Medicine); Nobuyoshi Yamamura (Department of Gastroenterology, Suwa Red Cross Hospital). 


\section{ABSTRACT}

Along with twin and family studies, recent genome-wide association studies suggest that genetic factors contribute to the susceptibility and severity of primary biliary cirrhosis (PBC). Although several reports have demonstrated that the $H L A D R B 1^{*} 08: 03$ allele is associated with disease susceptibility in Japan, the precise analysis of HLA haplotypes and the role of amino acid alignment have not been fully clarified. We investigated HLA class I A, B, and C and HLA class II DRB1 and DQB1 alleles and haplotypes in 229 Japanese patients with PBC and compared them with the published data of 523 healthy subjects. Significant associations were found with PBC susceptibility for the $D R B 1{ }^{*} 08: 03-D Q B 1 * 06: 01$ haplotype [13\% vs. $6 \%, P=0.000025$; odds ratio $\left.(\mathrm{OR})=2.22\right]$ and $D R B 1^{*} 04: 05-D Q B 1^{*} 04: 01$ haplotype $(17 \%$ vs. $13 \%, P=0.044 ; \mathrm{OR}=1.38)$. Conversely, there were significant protective associations with the $D R B 1 * 13: 02-D Q B 1{ }^{*} 06: 04$ haplotype $(2 \%$ vs. $5 \%, P=0.00093 ; O R=0.27)$ and $D R B 1 * 11: 01-D Q B 1 * 03: 01$ haplotype $(1 \%$ vs. $4 \%, P=0.03 ; \mathrm{OR}=0.37)$. The frequency of the $D R B 1^{*} 09: 01-D Q B 1^{*} 03: 03$ haplotype was significantly higher in patients who had received orthotopic liver transplantation $(\mathrm{OLT})(33 \%$ vs. $11 \%, P=0.0012 ; \mathrm{OR}=3.96)$. Furthermore, the frequency of serine at position $57(P=0.0000015$; OR $=1.83)$ of the DR $\beta$ chain differed the most in patients with PBC compared with healthy subjects. 
Conclusion: This study established the role of HLA haplotypes in determining PBC susceptibility and progression in the Japanese population. Further re-sequencing of the HLA region is required to more precisely identify the genetic components of PBC. 
Primary biliary cirrhosis (PBC) is an autoimmune liver disease characterized by portal inflammation and immune-mediated destruction of intrahepatic bile ducts that often leads to cirrhosis and liver failure. ${ }^{1}$ Although twin and family studies suggest that genetic factors contribute to disease susceptibility and severity, ${ }^{2-3}$ the cause of PBC remains poorly understood. ${ }^{4}$ Significant associations of genetic factors, including HLA alleles, tumor necrosis factor $\alpha(\mathrm{TNF} \alpha)^{5-8}$ and cytotoxic T-lymphocyte antigen 4 (CTLA4), ${ }^{8-14}$ with PBC have been reported. Among these, only HLA has consistently been associated with PBC susceptibility. ${ }^{15}$ The HLA-DRB1*08 family of alleles has been the most frequently described determinant for susceptibility to PBC;16-21 HLA-DRB $1^{*} 08: 03$ has been associated with PBC in the Japanese. ${ }^{22-26}$ However, HLA DQB1 alleles and haplotypes have not been fully investigated, and large cohort studies have indicated that HLA-DRB1*11 and $D R B 1^{*} 13$ alleles were in fact protective against PBC. ${ }^{20-21,26}$ As recent genome-wide studies of PBC have shown the strongest association signals in the HLA region, ${ }^{27-30}$ we sought to determine if particular HLA alleles or haplotypes or DRB1 allele amino acid alignments were associated with susceptibility to PBC or disease progression in the Japanese population.

\section{Patients and Methods}




\section{Subjects.}

The clinical and biochemical features of 229 PBC patients who were enrolled for this study between January 2005 and September 2010 are shown in Table 1. The racial background of all patients was Japanese. HLA class I and class II allelic genotypes from 523 healthy subjects obtained in a previous study were available as controls. ${ }^{31}$ In addition, HLA class II allelic genotypes from 130 patients with chronic hepatitis C virus infection were adopted from another study as comparison cases having another liver disease. ${ }^{32}$ The diagnosis of PBC was based on criteria from the American Association for the Study of Liver Diseases. ${ }^{33}$ Serum anti-mitochondrial antibody was determined using indirect immunofluorescence, and a titer of $\geq 1: 40$ was considered to be positive. ${ }^{34}$ Our serological protocol did not include testing for particular anti-nuclear antibodies, such as ani-gp210 antibody reactivity, or anti-mitochondrial antibody titration. All patients were negative for hepatitis B surface antigen, antibody to hepatitis B core antigen, antibody to hepatitis C virus, and antibody to the human immunodeficiency virus. Patients were classified into two stages of PBC based on their most recent follow-up: early stage patients were histologically Scheuer stage I or II ${ }^{35}$ or of unknown histological stage without liver cirrhosis, and late stage patients were histologically Scheuer stage III or IV or clinically diagnosed with liver cirrhosis or hepatic failure. ${ }^{14}$ Liver cirrhosis was 
diagnosed by histological examination and/or characteristic clinical signs of advanced liver disease.$^{36}$ All subjects provided written informed consent for this study, which was approved by the institutional ethics committee.

\section{HLA class I and class II typing.}

Genomic DNA from patients and controls was isolated by phenolic extraction of sodium dodecyl sulfate-lyzed and proteinase K-treated cells, as described previously. ${ }^{37}$ HLA typing was carried out using a Luminex multi-analyzer profiling system with a LAB type ${ }^{\circledR}$ SSO One Lambda typing kit (One Lambda, Inc. Canoga Park, CA), which is based on polymerase chain reaction sequence-specific oligonucleotide probes. HLA genotypes were determined by sequence-based typing. Peptide sequences of all HLA-DRB1 alleles in the IMGT/HLA database release 3.4.0 (April 2011) were aligned.

\section{Statistical Analysis.}

Phenotype frequencies were estimated by direct counting for each HLA allele. The significance of an association was evaluated by determining both the standard and corrected $P$ values after $\chi^{2}$ analysis or Fisher's exact test. A threshold corrected $P$ value of less than 0.05 was considered statistically significant. Association strength was 
estimated by calculating the odds ratio (OR) and 95\% confidence interval $(\mathrm{Cl})$.

\section{Results}

\section{Distribution of HLA A, B, and C Alleles.}

Among HLA class I alleles, the frequencies of $A^{*} 02: 01$ and $C^{*} 03: 03$ were significantly increased in patients with PBC compared with healthy subjects (16\% vs. $11 \%, P=0.0029$ and $18 \%$ vs. $13 \%, P=0.012$, respectively) (Table 2 ). In contrast, patients had significantly lower frequencies of $A^{*} 02: 06$ (6\% vs. $\left.9 \%, P=0.038\right), A^{\star} 33: 03$ (4\% vs. $8 \%, P=0.0025), B^{*} 44: 03(2 \%$ vs. $7 \%, P=0.0011), C^{*} 08: 01(5 \%$ vs. $10 \%, P=$ $0.005), C * 14: 03(3 \%$ vs. $7 \%, P=0.0018)$, and $C * 15: 02(2 \%$ vs. $4 \%, P=0.03)$ alleles compared with controls (Table 2). No other HLA A, B, or C alleles differed significantly between the groups.

\section{Distribution of HLA-DRB1 and DQB1 Alleles.}

Among DRB1 alleles, $D R B 1^{*} 04: 05$ and $D R B 1^{*} 08: 03$ were significantly associated with PBC compared with healthy subjects (17\% vs. $13 \%, P=0.044$ and $13 \%$ vs. $6 \%, P=0.000025$, respectively) (Table 2). Patients with PBC had a significantly lower frequency of $D R B 1 * 11: 01(1 \%$ vs. $4 \%, P=0.02)$ and $D R B 1 * 13: 02(3 \%$ vs. $6 \%, P=$ 
0.029) allele carriage compared with controls (Table 2). Among DQB1 alleles, the $D Q B 1^{*} 04: 01$ and $D Q B 1^{*} 06: 01$ alleles were significantly associated with an increased risk of PBC (18\% vs. $13 \%, P=0.02$ and $23 \%$ vs. $15 \%, P=0.000091$, respectively) (Table 2). Conversely, $D Q B 1^{\star} 03: 01$ (6\% vs. $\left.12 \%, P=0.00027\right), D Q B 1{ }^{*} 06: 02(7 \%$ vs. $12 \%, P=0.019)$, and $D Q B 1^{*} 06: 04(2 \%$ vs. $5 \%, P=0.0041)$ all conferred a reduced risk of PBC occurrence (Table 2). No other HLA DRB1 or DQB1 alleles were significantly associated with PBC compared with healthy subjects. We also examined the influence of DRB1 and DQB1 allele homozygosity with PBC susceptibility and protection, but found no significant associations. However, the $D R B 1^{\star} 08: 03$ and $D Q B 1^{*} 06: 01$ alleles were significantly associated with PBC compared to comparison cases with chronic hepatitis C (13\% vs. $5 \%, P=0.0017$ and $23 \%$ vs. $16 \%, P=0.02$, respectively) (Supplementary Table 1). Conversely, $D Q B 1^{*} 03: 01$ and $D Q B 1^{*} 06: 04$ had significantly lower frequencies in patients with PBC than in chronic hepatitis $C$ controls $(6 \%$ vs. $12 \%, P=0.0076$ and $2 \%$ vs. $5 \%, P=0.041)$ (Supplementary Table 1).

\section{Distribution of Haplotypes among PBC Patients and Controls.}

The frequency of the $D R B 1^{*} 08: 03-D Q B 1^{*} 06: 01$ haplotype in patients with PBC was $13 \%$ and significantly higher than the $6 \%$ observed in healthy subjects $(P=$ 
0.000025; OR = 2.22) (Table 3). However, there was no significant difference between the groups regarding the $D R B 1^{*} 15: 02-D Q B 1 * 06: 01$ haplotype (10\% vs. $\left.9 \%, P=0.45\right)$. There was also a modest relationship between carriage of the $D R B 1^{\star} 04: 05-D Q B 1^{*} 04: 01$ haplotype and disease susceptibility (17\% vs. $13 \%, P=0.044$; OR $=1.38)$. In contrast, protective effects were seen for the $D R B 1^{*} 13: 02-D Q B 1{ }^{*} 06: 04$ haplotype (2\% vs. $5 \%, P$ $=0.00093 ; \mathrm{OR}=0.27)$ and $D R B 1 * 11: 01-D Q B 1 * 03: 01$ haplotype $(1 \%$ vs. $4 \%, P=0.03$; $\mathrm{OR}=0.37)$ in our cohort.

\section{Association between HLA and Clinical Findings.}

PBC patients were stratified according to history of orthotopic liver transplantation (OLT) and disease progression. The HLA-DRB1 ${ }^{*} 09: 01$ and $D Q B 1^{*} 03: 03$ alleles (33\% vs. $11 \%, P=0.0012$ and $33 \%$ vs. $12 \%, P=0.0022$, respectively) and the $D R B 1^{*} 09: 01-D Q B 1{ }^{*} 03: 03$ haplotype $(33 \%$ vs. $11 \%, P=0.0012 ; \mathrm{OR}=3.96 ; 95 \% \mathrm{Cl}$ 1.75-8.95) were all significantly associated with OLT (Table 4). Homozygosity for the $D R B 1^{*} 09: 01$ and $D Q B 1^{*} 03: 03$ alleles $(43 \%$ vs. $4 \%, P=0.0012$ and $43 \%$ vs. $4 \%, P=$ 0.00076 , respectively) and the $D R B 1^{*} 09: 01-D Q B 1^{*} 03: 03$ haplotype $(43 \%$ vs. $4 \%, P=$ $0.0012 ; \mathrm{OR}=16.50 ; 95 \% \mathrm{Cl} 2.10-129.63)$ was significantly correlated with OLT. When PBC patients with cirrhosis $(n=42)$ were compared to those without $(n=187)$, similar 
significant genetic associations of the $D R B 1^{*} 09: 01$ and $D Q B 1^{*} 03: 03$ alleles $(23 \%$ vs. $10 \%, P=0.0043$ and $23 \%$ vs. $11 \%, P=0.0094$, respectively), and the $D R B 1{ }^{*} 09: 01-D Q B 1{ }^{*} 03: 03$ haplotype (23\% vs. $10 \% ; P=0.0043, \mathrm{OR}=2.51 ; 95 \% \mathrm{Cl} 1.37$

- 4.62) with disease progression were found (Table 4). Homozygosity for the $D R B 1{ }^{*} 09: 01$ and $D Q B 1{ }^{*} 03: 03$ alleles $(27 \%$ vs. $3 \%, P=0.007$ and $27 \%$ vs. $2 \%, P=$ 0.0049 , respectively) and the $D R B 1^{*} 09: 01-D Q B 1^{*} 03: 03$ haplotype $(27 \%$ vs. $3 \%, P=$ $0.007 ; \mathrm{OR}=13.45 ; 95 \% \mathrm{Cl} 1.36-133.18)$ was significantly correlated with cirrhosis as well. No other HLA class I or class II alleles or haplotypes were significantly associated with disease progression.

\section{Distribution of DRB1 Amino Acid Residues.}

The amino acid sequence encoded by the second exon of $H L A-D R B 1$ was determined for each subject. As shown in Table 5, the prevalence of glycine at position $13(P=0.0013 ; \mathrm{OR}=1.60)$, tyrosine at position $16(P=0.0013 ; \mathrm{OR}=1.60)$ and position $47(P=0.00017 ; \mathrm{OR}=1.62)$, serine at position $57(P=0.0000015 ; \mathrm{OR}=1.83)$, and leucine at position $74(P=0.0000069$; OR $=2.01)$ was significantly higher in patients with PBC compared with healthy subjects. In contrast, serine at position $13(P=$ $0.000037 ; \mathrm{OR}=0.51)$, histidine at position $16(P=0.0029 ; \mathrm{OR}=0.66)$, and 
phenylalanine at position $47(P=0.000096$; OR $=0.61)$ conferred protection against the disease.

Analysis of the amino acid residues encoded by $D R B 1^{*} 09: 01$ revealed 6 unique differences from those encoded by other DRB1 alleles: Iysine at position 9, aspartic acid at position 11 , tyrosine at position 26 , histidine at position 28 , glycine at position 30 , and valine at position 78 (Table 6).

\section{Discussion}

The present study examined HLA class I and class II alleles and haplotypes and amino acid residues in patients with PBC in the Japanese population. Our key findings were as follows: (1) the $\mathrm{HLA} D R B 1^{*} 08: 03-D Q B 1{ }^{*} 06: 01$ haplotype was significantly associated with disease pathogenesis, which was in agreement with several Japanese studies linking $D R B 1^{*} 08: 03$ with PBC; (2) Japanese PBC patients had significantly lower frequencies of HLA DRB1*13:02-DQB1*06:04 and DRB1*11:01-DQB1*03:01 haplotypes, suggesting protection by these haplotypes to the disease as indicated by recent reports in Europe; (3) the existence of a relationship between HLA haplotype and OLT and disease progression; and (4) PBC-associated alleles have specific antigen presentation profiles. 
The HLA $D R B 1^{*} 08: 03(P=0.000025)$ and $D Q B 1^{*} 06: 01(P=0.000091)$ alleles were strongly associated with PBC susceptibility. Although a relationship between $D R B 1^{*} 08: 03$ and PBC has already been reported in the Japanese, an association with the $D Q B 1^{*} 06: 01$ allele has not been investigated in a large cohort like ours. $D Q B 1: 06: 01$ is known to be in linkage disequilibrium with $D R B 1^{*} 08: 03$ or $D R B 1^{*} 15: 02$ in the Japanese population. Our data clearly show that the $D R B 1^{\star} 08: 03-D Q B 1^{*} 06: 01$ haplotype was significantly associated with PBC $(P=0.000025)$, but the $D R B 1^{*} 15: 02-D Q B 1{ }^{*} 06: 01$ haplotype was not. This suggests that the $D R B 1^{*} 08: 03$ allele and/or the $D R B 1^{*} 08: 03-D Q B 1^{\star} 06: 01$ haplotype might play a crucial role in PBC development in Japan. However, since $D R B 1^{*} 08: 03$ was found in only $13 \%$ of PBC patients in this study, other candidate genes and environmental factors require further study. The $D R B 1^{*} 04: 05-D Q B 1^{*} 04: 01$ haplotype was also found to be weakly associated with susceptibility to PBC. Since our prior reports showed that this haplotype was strongly associated with autoimmune hepatitis and autoimmune pancreatitis in the Japanese,,$^{38-39}$ deeper evaluation of $D R B 1^{*} 04: 05-D Q B 1^{*} 04: 01$ with regard to autoimmune diseases and PBC may uncover key relationships of clinical value. Recently, genome-wide association studies showed that HLA and other non-HLA genes were associated with susceptibility to PBC in Europe and North America. ${ }^{27-30}$ Accordingly, 
similar studies are now being performed to clarify the genes responsible for PBC in Japan.

This study showed for the first time that the $D R B 1^{*} 13: 02-D Q B 1^{*} 06: 04$ and $D R B 1{ }^{*} 11: 01-D Q B 1{ }^{*} 03: 01$ haplotypes played protective roles against PBC in the Japanese population. Our data support the recent consensus that DRB1*11 and ${ }^{*} 13$ confer resistance in Europe and Japan, ${ }^{20-21,26}$ although we cannot exclude the possibility that these associations are only linkage markers for a yet undefined gene for PBC. Multiple lines of evidence show that DRB1*11 and DRB1*13 alleles are also protective against several infectious diseases. Since bacterial infections have been reported as possible causes of PBC, ${ }^{40-41} \mathrm{HLA}$ alleles or haplotypes that are resistant to such agents might influence protection against PBC development. ${ }^{15}$

Interestingly, this study revealed a novel association between the $D R B 1{ }^{*} 09: 01-D Q B 1{ }^{*} 03: 03$ haplotype and PBC progression. Although Nakamura et al. ${ }^{26}$ reported that $D R B 1^{*} 09: 01$ was associated with disease progression of non-jaundice type PBC, there have been no reports of a connection between HLA haplotypes and OLT or cirrhosis in Japan. Several studies from the United Kingdom and Sweden ${ }^{19,} 42$ have reported that $D R B 1^{*} 08: 01$ is associated with both susceptibility and progression to the disease, but a study from Italy could not confirm this. ${ }^{21}$ Homozygosity of the 
$D R B 1^{*} 09: 01-D Q B 1^{*} 03: 03$ haplotype was also associated with disease progression in our cohort. The reasons for this observation are unknown; however, the association of this particular HLA haplotype and disease progression is striking. Since only 15 (7\%) and $42(18 \%)$ of our 229 patients had OLT and cirrhosis, respectively, further longitudinal follow-up studies in larger cohorts from different ethnicities are required. A recent study uncovered that anti-gp210 and anti-centromere antibodies may be risk factors for the progression of PBC. ${ }^{43}$ It would be of interest to assess associations between these autoantibodies and HLA haplotypes in the future.

Lastly, the present study determined and analyzed the amino acid sequence encoded by the HLA-DRB1 allele in relation to disease susceptibility. The incidence of glycine- 13 , tyrosine- 16 , and leucine- 74 encoded by $D R B 1^{\star} 08: 03$ was higher and that of serine-13, histidine-16, and phenylalanine- 47 encoded by $D R B 1^{*} 11$ and $D R B 1^{*} 13$ was lower in PBC patients. These data are consistent with a report by Donaldson et al. ${ }^{20}$ Serine-57 had the highest frequency among patients in our cohort $(P=0.0000004)$, likely because it is encoded by $D R B 1^{*} 04: 05$ and $D R B 1^{*} 08: 03$, which are both significantly associated with PBC susceptibility in the Japanese. Serine- 57 relevance was not found in a European study ${ }^{20}$ probably since frequencies of the DRB $1{ }^{*} 04$ and DRB $1{ }^{*} 08$ alleles therein were found in $10 \%$ and $7 \%$, respectively, of patients. ${ }^{21}$ The amino acid residue at 
position 57 influences the binding of antigen side chains associated with the 9th pocket of the expressed DR molecule, which might factor predominantly in susceptibility to PBC in Japanese cases. Interestingly, amino acid residues lysine-9, aspartic acid-11, tyrosine-26, histidine-28, glycine-30, and valine-78 were encoded by $D R B 1^{*} 09: 01$ only, suggesting that some or all of these may contribute to disease progression in Japanese patients.

In conclusion, the $D R B 1^{*} 08: 03-D Q B 1{ }^{*} 06: 01$ haplotype, $D R B 1 * 13: 02-D Q B 1{ }^{*} 06: 04$ haplotype, and $D R B 1 * 11: 01-D Q B 1 * 03: 01$ haplotype are associated with either PBC susceptibility or protection in the Japanese population. $D R B 1^{*} 09: 01-D Q B 1^{*} 03: 03$ is a novel haplotype associated with the progression of PBC that has several uniquely expressed amino acids. Other specific amino acid residues in the DR $\beta$ chain appear to contribute to susceptibility or resistance to PBC. Genome-wide analysis and re-sequencing of the entire HLA region will be necessary to provide more precise genetic information on susceptibility to PBC in Japan.

Acknowledgment: The authors thank Yuki Akahane and Asami Yamazaki for their technical assistance, and Trevor Ralph for his editorial assistance. 


\section{References}

1. Kaplan MM, Gershwin ME. Primary biliary cirrhosis. N Engl J Med 2005;353:1261-1273.

2. Selmi C, Mayo MJ, Bach N, Ishibashi H, Invernizzi P, Gish RG, et al. Primary biliary cirrhosis in monozygotic and dizygotic twins: genetics, epigenetics, and environment. Gastroenterology 2004;127:485-492.

3. Invernizzi P, Selmi C, Mackay IR, Podda M, Gershwin ME. From bases to basis: linking genetics to causation in primary biliary cirrhosis. Clin Gastroenterol Hepatol 2005;3:401-410.

4. Gershwin ME, Mackay IR. The causes of primary biliary cirrhosis: Convenient and inconvenient truths. Hepatology 2008;47:737-745.

5. Donaldson PT. TNF gene polymorphisms in primary biliary cirrhosis: a critical appraisal. J Hepatol 1999;31:366-368.

6. Tanaka A, Quaranta S, Mattalia A, Coppel R, Rosina F, Manns M, et al. The tumor necrosis factor-alpha promoter correlates with progression of primary biliary cirrhosis. J Hepatol 1999;30:826-829.

7. Neuman M, Angulo P, Malkiewicz I, Jorgensen R, Shear N, Dickson ER, et al. Tumor necrosis factor-alpha and transforming growth factor-beta reflect severity of liver damage in primary biliary cirrhosis. J Gastroenterol Hepatol 2002;17:196-202.

8. Juran BD, Atkinson EJ, Larson JJ, Schlicht EM, Liu X, Heathcote EJ, et al. Carriage of a tumor necrosis factor polymorphism amplifies the cytotoxic T-lymphocyte antigen 4 attributed risk of primary biliary cirrhosis: evidence for a gene-gene interaction. Hepatology 2010;52:223-229.

9. Agarwal K, Jones DE, Daly AK, James OF, Vaidya B, Pearce S, et al. CTLA-4 gene polymorphism confers susceptibility to primary biliary cirrhosis. J Hepatol 2000;32:538-541.

10. Bittencourt PL, Palacios SA, Farias AQ, Abrantes-Lemos CP, Cancado EL, Carrilho FJ, et al. Analysis of major histocompatibility complex and CTLA-4 alleles in Brazilian patients with primary biliary cirrhosis. J Gastroenterol Hepatol 2003;18:1061-1066.

11. Donaldson P, Veeramani S, Baragiotta A, Floreani A, Venturi C, Pearce S, et al. Cytotoxic T-lymphocyte-associated antigen-4 single nucleotide polymorphisms and haplotypes in primary biliary cirrhosis. Clin Gastroenterol Hepatol 2007;5:755-760.

12. Poupon R, Ping C, Chretien Y, Corpechot C, Chazouilleres O, Simon T, et al. Genetic factors of susceptibility and of severity in primary biliary cirrhosis. J Hepatol 2008;49:1038-1045.

13. Juran BD, Atkinson EJ, Schlicht EM, Fridley BL, Lazaridis KN. Primary biliary cirrhosis is associated with a genetic variant in the $3^{\prime}$ flanking region of the CTLA4 gene. Gastroenterology 2008;135:1200-1206.

14. Joshita S, Umemura T, Yoshizawa K, Katsuyama Y, Tanaka E, Nakamura M, et al. Association analysis of cytotoxic T-lymphocyte antigen 4 gene polymorphisms with primary biliary cirrhosis in Japanese patients. J Hepatol 2010;53:537-541. 
15. Invernizzi P. Human leukocyte antigen in primary biliary cirrhosis: An old story now reviving. Hepatology 2011;54:714-723.

16. Gores GJ, Moore SB, Fisher LD, Powell FC, Dickson ER. Primary biliary cirrhosis: associations with class II major histocompatibility complex antigens. Hepatology 1987;7:889-892.

17. Manns MP, Bremm A, Schneider PM, Notghi A, Gerken G, Prager-Eberle M, et al. HLA DRw8 and complement C4 deficiency as risk factors in primary biliary cirrhosis. Gastroenterology 1991;101:1367-1373.

18. Underhill J, Donaldson P, Bray G, Doherty D, Portmann B, Williams R. Susceptibility to primary biliary cirrhosis is associated with the HLA-DR8-DQB1*0402 haplotype. Hepatology 1992;16:1404-1408.

19. Donaldson P, Agarwal K, Craggs A, Craig W, James O, Jones D. HLA and interleukin 1 gene polymorphisms in primary biliary cirrhosis: associations with disease progression and disease susceptibility. Gut 2001;48:397-402.

20. Donaldson PT, Baragiotta A, Heneghan MA, Floreani A, Venturi C, Underhill JA, et al. HLA class II alleles, genotypes, haplotypes, and amino acids in primary biliary cirrhosis: a large-scale study. Hepatology 2006;44:667-674.

21. Invernizzi P, Selmi C, Poli F, Frison S, Floreani A, Alvaro D, et al. Human leukocyte antigen polymorphisms in Italian primary biliary cirrhosis: a multicenter study of 664 patients and 1992 healthy controls. Hepatology 2008;48:1906-1912.

22. Seki T, Kiyosawa K, Ota M, Furuta S, Fukushima H, Tanaka E, et al. Association of primary biliary cirrhosis with human leukocyte antigen DPB1 ${ }^{*} 0501$ in Japanese patients. Hepatology 1993;18:73-78.

23. Onishi S, Sakamaki T, Maeda T, Iwamura S, Tomita A, Saibara T, et al. DNA typing of HLA class II genes; DRB1*0803 increases the susceptibility of Japanese to primary biliary cirrhosis. J Hepatol 1994;21:1053-1060.

24. Oguri H, Oba S, Ogino H, Inagaki $\mathrm{Y}$, Kaneko S, Unoura M. Susceptibility to primary biliary cirrhosis is associated with human leucocyte antigen $D R B 1^{*} 0803$ in Japanese patients. Int Hepatol Comm 1994;2:263-270.

25. Mukai T, Kimura A, Ishibashi $\mathrm{H}$, Sasazuki T, Sata M, Maruyama T. Association of $D R B 1^{*} 0803$ and *1602 with susceptibility to primary biliary cirrhosis. Int Hepatol Comm 1995;3:207-212.

26. Nakamura M, Yasunami M, Kondo H, Horie H, Aiba Y, Komori A, et al. Analysis of HLA-DRB1 polymorphisms in Japanese patients with primary biliary cirrhosis (PBC): The HLA-DRB1polymorphism determines the relative risk of antinuclear antibodies for disease progression in PBC. Hepatol Res 2010;40:494-504.

27. Hirschfield GM, Liu X, Xu C, Lu Y, Xie G, Gu X, et al. Primary biliary cirrhosis associated with HLA, IL12A, and IL12RB2 variants. N Engl J Med 2009;360:2544-2555.

28. Hirschfield GM, Liu X, Han Y, Gorlov IP, Lu Y, Xu C, et al. Variants at IRF5-TNPO3, 17q12-21 and MMEL1 are associated with primary biliary cirrhosis. Nat Genet 2010;42:655-657. 
29. Liu X, Invernizzi P, Lu Y, Kosoy R, Bianchi I, Podda M, et al. Genome-wide meta-analyses identify three loci associated with primary biliary cirrhosis. Nat Genet 2010;42:658-660.

30. Mells GF, Floyd JA, Morley KI, Cordell HJ, Franklin CS, Shin SY, et al. Genome-wide association study identifies 12 new susceptibility loci for primary biliary cirrhosis. Nat Genet 2011;43:329-332.

31. Nakajima F, Nakamura J, Yokota T. Analaysis of HLA haplotypes in Japanese, using high resolution allele typing. MHC 2001;8:1-32.

32. Kuzushita N, Hayashi N, Moribe T, Katayama K, Kanto T, Nakatani S, et al. Influence of HLA haplotypes on the clinical courses of individuals infected with hepatitis $C$ virus. Hepatology 1998;27:240-244.

33. Lindor KD, Gershwin ME, Poupon R, Kaplan M, Bergasa NV, Heathcote EJ. Primary biliary cirrhosis. Hepatology 2009;50:291-308.

34. Umemura T, Zen Y, Hamano H, Kawa S, Nakanuma Y, Kiyosawa K. Immunoglobin G4-hepatopathy: association of immunoglobin G4-bearing plasma cells in liver with autoimmune pancreatitis. Hepatology 2007;46:463-471.

35. Scheuer P. Primary biliary cirrhosis. Proc R Soc Med 1967;60:1257-1260.

36. Umemura T, Tanaka E, Ostapowicz G, Brown KE, Heringlake S, Tassopoulos NC, et al. Investigation of SEN virus infection in patients with cryptogenic acute liver failure, hepatitis-associated aplastic anemia, or acute and chronic non-A-E hepatitis. J Infect Dis 2003;188:1545-1552.

37. Ota M, Seki T, Nomura N, Sugimura K, Mizuki N, Fukushima H, et al. Modified PCR-RFLP method for HLA-DPB1 and -DQA1 genotyping. Tissue Antigens 1991;38:60-71.

38. Seki T, Ota M, Furuta S, Fukushima H, Kondo T, Hino K, et al. HLA class II molecules and autoimmune hepatitis susceptibility in Japanese patients. Gastroenterology 1992;103:1041-1047.

39. Kawa S, Ota M, Yoshizawa K, Horiuchi A, Hamano H, Ochi Y, et al. HLA DRB10405-DQB10401 haplotype is associated with autoimmune pancreatitis in the Japanese population. Gastroenterology 2002;122:1264-1269.

40. Selmi C, Balkwill DL, Invernizzi P, Ansari AA, Coppel RL, Podda M, et al. Patients with primary biliary cirrhosis react against a ubiquitous xenobiotic-metabolizing bacterium. Hepatology 2003;38:1250-1257.

41. Invernizzi P, Selmi C, Gershwin ME. Update on primary biliary cirrhosis. Dig Liver Dis 2010;42:401-408.

42. Wassmuth R, Depner F, Danielsson A, Hultcrantz R, Loof L, Olson R, et al. HLA class II markers and clinical heterogeneity in Swedish patients with primary biliary cirrhosis. Tissue Antigens 2002;59:381-387.

43. Nakamura $M$, Kondo $H$, Mori T, Komori A, Matsuyama $M$, Ito $M$, et al. Anti-gp210 and anti-centromere antibodies are different risk factors for the progression of primary biliary cirrhosis. Hepatology 2007;45:118-127. 
Table 1. Demographic and Clinical Characteristics of Patients with PBC

\begin{tabular}{lcc}
\hline Characteristics & \multicolumn{2}{c}{ PBC } \\
& $(\mathrm{n}=229)$ \\
\hline Median age, years (range) & 57 & $(27-86)$ \\
Female, n (\%) & 204 & $(89 \%)$ \\
Late stage of disease, $\mathrm{n}(\%)$ & 50 & $(22 \%)$ \\
Cirrhosis, n (\%) & 42 & $(18 \%)$ \\
OLT, n (\%) & 15 & $(7 \%)$ \\
Serum AMA-positive, $\mathrm{n}(\%)$ & 209 & $(91 \%)$ \\
\hline
\end{tabular}

Abbreviations: OLT, orthotopic liver transplantation; AMA, anti-mitochondrial antibody. 
Table 2. Statistical Analysis of Representative HLA Antigens among Patients with PBC and Healthy Subjects

\begin{tabular}{|c|c|c|c|c|}
\hline \multirow[t]{2}{*}{ HLA } & \multicolumn{2}{|c|}{ Frequency (\%) } & \multirow[t]{2}{*}{$P$ value } & \multirow[t]{2}{*}{ OR (95\% Cl) } \\
\hline & $\begin{array}{l}\text { Patients with PBC } \\
\qquad(2 \mathrm{n}=458)\end{array}$ & $\begin{array}{l}\text { Healthy subjects } \\
(2 \mathrm{n}=1032-1046)\end{array}$ & & \\
\hline$A^{*} 02: 01$ & 16 & 11 & 0.0029 & $1.63(1.19-2.24)$ \\
\hline$A^{*} 02: 06$ & 6 & 9 & 0.038 & $0.61(0.39-0.95)$ \\
\hline$A * 33: 03$ & 4 & 8 & 0.0025 & $0.43(0.25-0.74)$ \\
\hline$B^{*} 44: 03$ & 2 & 7 & 0.0011 & $0.34(0.18-0.65)$ \\
\hline$C^{*} 03: 03$ & 18 & 13 & 0.012 & $1.48(1.10-1.99)$ \\
\hline$C^{*} 08: 01$ & 5 & 10 & 0.005 & $0.51(0.32-0.81)$ \\
\hline$C^{*} 14: 03$ & 3 & 7 & 0.0018 & $0.38(0.21-0.70)$ \\
\hline$C * 15: 02$ & 2 & 4 & 0.03 & $0.44(0.21-0.90)$ \\
\hline$D R B 1 * 04: 05$ & 17 & 13 & 0.044 & $1.38(1.02-1.87)$ \\
\hline$D R B 1^{*} 08: 03$ & 13 & 6 & 0.000025 & $2.22(1.53-3.20)$ \\
\hline$D R B 1 * 11: 01$ & 1 & 4 & 0.02 & $0.35(0.15-0.83)$ \\
\hline$D R B 1 * 13: 02$ & 3 & 6 & 0.029 & $0.49(0.27-0.91)$ \\
\hline$D Q B 1{ }^{*} 03: 01$ & 6 & 12 & 0.00027 & $0.44(0.29-0.69)$ \\
\hline$D Q B 1{ }^{*} 04: 01$ & 18 & 13 & 0.02 & $1.45(1.07-1.95)$ \\
\hline$D Q B 1 * 06: 01$ & 23 & 15 & 0.000091 & $1.75(1.32-2.30)$ \\
\hline$D Q B 1^{*} 06: 02$ & 7 & 12 & 0.019 & $0.61(0.41-0.91)$ \\
\hline$D Q B 1 * 06: 04$ & 2 & 5 & 0.0041 & $0.35(0.17-0.72)$ \\
\hline
\end{tabular}

Abbreviations: OR, odds ratio; $\mathrm{Cl}$, confidence interval. 
Table 3. Haplotype Distribution in PBC Patients and Healthy Subjects

\begin{tabular}{|c|c|c|c|c|c|}
\hline \multicolumn{2}{|c|}{ Allele at each locus } & \multirow{3}{*}{$\begin{array}{l}\text { Patients } \\
\text { with PBC } \\
2 n=458\end{array}$} & \multirow{3}{*}{$\begin{array}{l}\text { Healthy } \\
\text { subjects } \\
2 \mathrm{n}=1032\end{array}$} & \multirow{3}{*}{$P$ value } & \multirow{3}{*}{ OR $(95 \% \mathrm{Cl})$} \\
\hline & & & & & \\
\hline$D R B 1$ & $D Q B 1$ & & & & \\
\hline${ }^{*} 08: 03$ & ${ }^{*} 06: 01$ & $60(13 \%)$ & $66(6 \%)$ & 0.000025 & $2.22(1.53-3.20)$ \\
\hline${ }^{*} 04: 05$ & ${ }^{*} 04: 01$ & $79(17 \%)$ & $136(13 \%)$ & 0.044 & $1.38(1.02-1.87)$ \\
\hline *13:02 & ${ }^{*} 06: 04$ & $7(2 \%)$ & $56(5 \%)$ & 0.00093 & $0.27(0.12-0.60)$ \\
\hline${ }^{*} 11: 01$ & ${ }^{*} 03: 01$ & $6(1 \%)$ & $36(4 \%)$ & 0.03 & $0.37(0.15-0.88)$ \\
\hline *15:02 & ${ }^{*} 06: 01$ & $47(10 \%)$ & $92(9 \%)$ & 0.47 & \\
\hline *09:01 & ${ }^{*} 03: 03$ & $58(13 \%)$ & $138(13 \%)$ & 0.77 & \\
\hline
\end{tabular}

Abbreviations: OR, odds ratio; $\mathrm{Cl}$, confidence interval. 
Table 4. HLA allele and Haplotype Distribution for OLT Status and Clinical Disease Progression

\begin{tabular}{|c|c|c|c|c|c|c|c|}
\hline \multicolumn{2}{|c|}{ Allele at each locus } & OLT & Non-OLT & $P$ value & Cirrhosis & Non-cirrhosis & $P$ value \\
\hline$D R B 1$ & $D Q B 1$ & $2 n=30$ & $2 n=428$ & & $2 n=84$ & $2 n=372$ & \\
\hline \multirow[t]{2}{*}{ *09:01 } & & $10(33 \%)$ & $48(11 \%)$ & 0.0012 & $19(23 \%)$ & $39(10 \%)$ & 0.0043 \\
\hline & ${ }^{\star} 03: 03$ & $10(33 \%)$ & $51(12 \%)$ & 0.0022 & $19(23 \%)$ & $42(11 \%)$ & 0.0094 \\
\hline *09:01 & *03:03 & $10(33 \%)$ & $48(11 \%)$ & 0.0012 & $19(23 \%)$ & $39(10 \%)$ & 0.0043 \\
\hline *08:03 & ${ }^{\star} 06: 01$ & $6(20 \%)$ & $54(13 \%)$ & 0.38 & $8(10 \%)$ & $52(14 \%)$ & 0.37 \\
\hline${ }^{*} 04: 05$ & ${ }^{*} 04: 01$ & $5(17 \%)$ & $76(18 \%)$ & 0.92 & $9(11 \%)$ & 72 (19\%) & 0.09 \\
\hline
\end{tabular}

Abbreviations: OLT, orthotopic liver transplantation; OR, odds ratio; Cl, confidence interval. 
Table 5. Frequency of Different Amino Acids at HLA DRB1

\begin{tabular}{|c|l|c|c|c|c|}
\hline \multirow{2}{*}{ Residue } & \multirow{2}{*}{ Amino acid } & PBC & Healthy & \\
& & $2 n=458$ & subjects & P value & OR $(95 \% \mathrm{CI})$ \\
\hline 13 & Glycine & $98(21 \%)$ & $150(15 \%)$ & 0.0013 & $1.60(1.21-2.12)$ \\
\hline & Serine & $55(12 \%)$ & $214(21 \%)$ & 0.000072 & $0.52(0.38-0.72)$ \\
\hline 16 & Tyrosine & $98(21 \%)$ & $150(15 \%)$ & 0.0013 & $1.60(1.21-2.12)$ \\
\hline 47 & Histidine & $346(76 \%)$ & $850(82 \%)$ & 0.0029 & $0.66(0.51-0.86)$ \\
\hline & Tyrosine & $344(75 \%)$ & $672(65 \%)$ & 0.00017 & $1.62(0.26-2.07)$ \\
\hline 57 & Shenylalanine & $114(25 \%)$ & $364(35 \%)$ & 0.00017 & $0.62(0.48-0.79)$ \\
\hline 74 & Lerine & $157(34 \%)$ & $224(22 \%)$ & 0.0000004 & $1.88(1.48-2.40)$ \\
\hline
\end{tabular}

Abbreviations: OR, odds ratio; $\mathrm{Cl}$, confidence interval. 
Table 6. Amino Acid Differences between the DRB1*09:01 Allele and Other HLA DRB1 Alleles

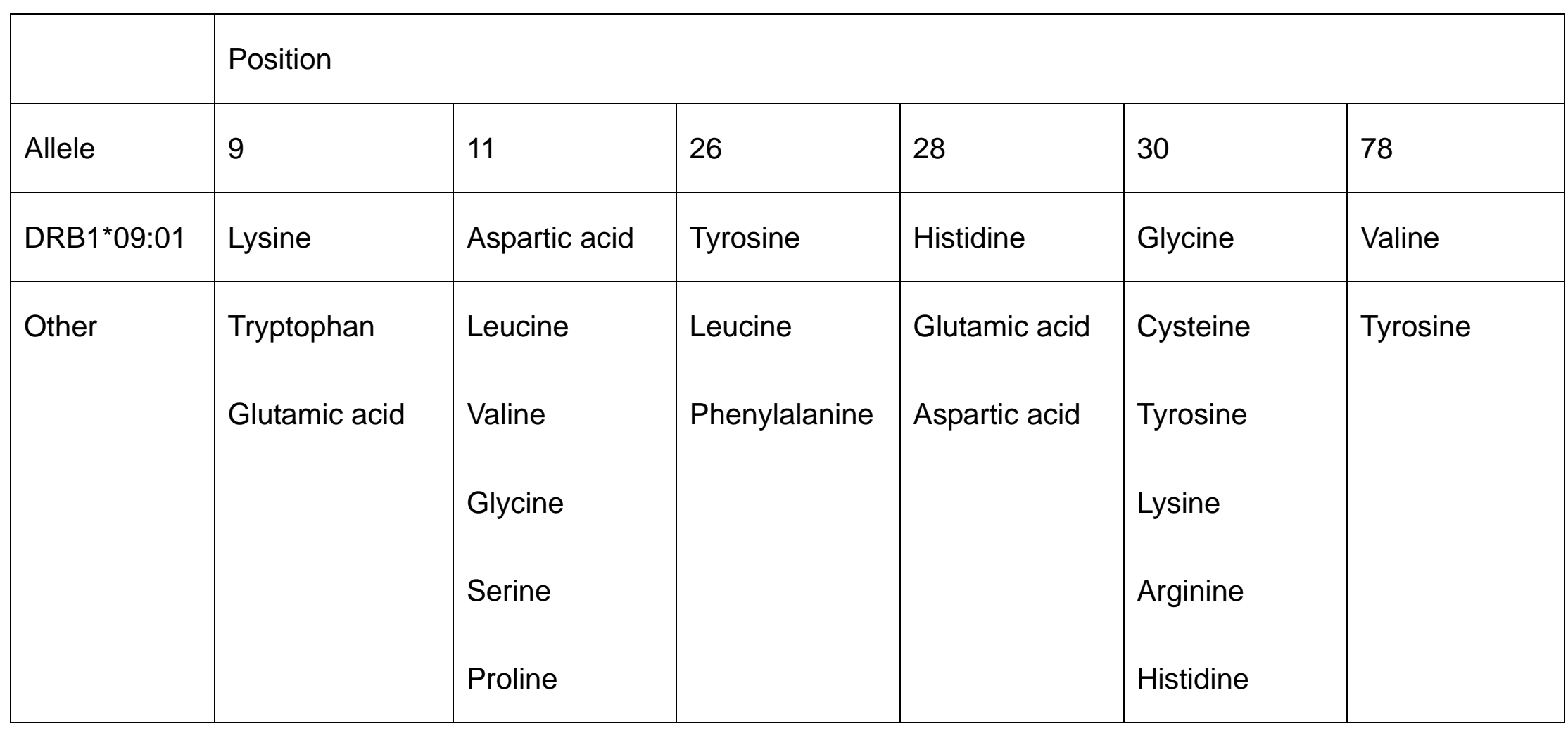


Supplementary Table 1. Statistical Analysis of Representative HLA Class II Antigens among Patients with PBC and Chronic Hepatitis C Virus Infection

\begin{tabular}{|c|c|c|c|c|}
\hline \multirow[t]{2}{*}{ HLA } & \multicolumn{2}{|c|}{ Frequency (\%) } & \multirow[t]{2}{*}{$P$ value } & \multirow[t]{2}{*}{ OR $(95 \% \mathrm{Cl})$} \\
\hline & $\begin{array}{l}\text { Patients with PBC } \\
\qquad(2 \mathrm{n}=458)\end{array}$ & $\begin{array}{l}\text { Patients with HCV Infection } \\
\qquad(2 n=260)\end{array}$ & & \\
\hline$D R B 1^{*} 04: 05$ & 17 & 21 & 0.29 & $0.80(0.54-1.17)$ \\
\hline$D R B 1^{*} 08: 03$ & 13 & 5 & 0.0017 & $2.65(1.45-4.84)$ \\
\hline$D R B 1 * 11: 01$ & 1 & 4 & 0.096 & $0.37(0.13-1.05)$ \\
\hline$D R B 1 * 13: 02$ & 3 & 5 & 0.13 & $0.51(0.24-1.11)$ \\
\hline$D Q B 1{ }^{*} 03: 01$ & 6 & 12 & 0.0076 & $0.46(0.27-0.80)$ \\
\hline$D Q B 1{ }^{*} 04: 01$ & 18 & 21 & 0.36 & $0.82(0.56-1.20)$ \\
\hline$D Q B 11^{*} 06: 01$ & 23 & 16 & 0.020 & $1.63(1.09-2.42)$ \\
\hline$D Q B 1^{*} 06: 02$ & 7 & 6 & 0.49 & $1.31(0.70-2.45)$ \\
\hline$D Q B 1^{*} 06: 04$ & 2 & 5 & 0.041 & $0.38(0.16-0.90)$ \\
\hline
\end{tabular}

Abbreviations: $\mathrm{HCV}$, hepatitis $\mathrm{C}$ virus; $\mathrm{OR}$, odds ratio; $\mathrm{Cl}$, confidence interval. 